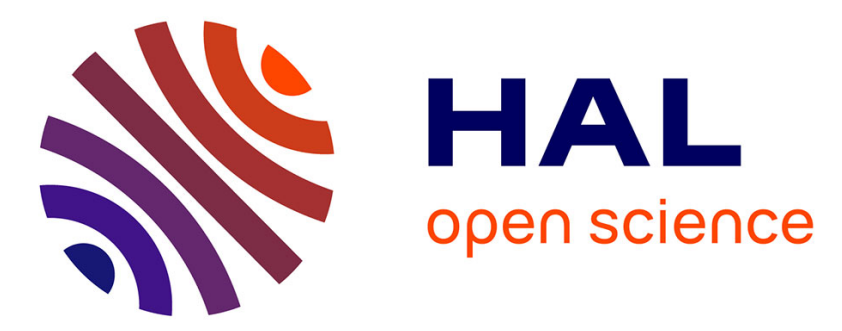

\title{
Ancient wheat varieties have a higher ability to interact with plant growth-promoting rhizobacteria
}

\author{
Jordan Valente, Florence Gerin, Jacques Le Gouis, Yvan Moënne-loccoz, \\ Claire Prigent-combaret
}

\section{- To cite this version:}

Jordan Valente, Florence Gerin, Jacques Le Gouis, Yvan Moënne-loccoz, Claire Prigent-combaret. Ancient wheat varieties have a higher ability to interact with plant growth-promoting rhizobacteria. Plant, Cell and Environment, 2020, 43 (1), pp.246-260. 10.1111/pce.13652 . hal-02337059

\section{HAL Id: hal-02337059 \\ https://hal.science/hal-02337059}

Submitted on 7 Dec 2020

HAL is a multi-disciplinary open access archive for the deposit and dissemination of scientific research documents, whether they are published or not. The documents may come from teaching and research institutions in France or abroad, or from public or private research centers.
L'archive ouverte pluridisciplinaire HAL, est destinée au dépôt et à la diffusion de documents scientifiques de niveau recherche, publiés ou non, émanant des établissements d'enseignement et de recherche français ou étrangers, des laboratoires publics ou privés.

\section{(c)(1)}

Distributed under a Creative Commons Attribution| 4.0 International License 
Modern breeding had a negative impact on the ability of wheat to interact with beneficial rootcolonizing bacteria termed PGPR, but this capacity has been maintained in a minority of modern cultivars. Breeding strategies should give further consideration to below-ground symbiotic interactions. 
7 7

\section{Ancient wheat varieties have a higher ability to interact with plant growth-promoting} rhizobacteria

Jordan Valente ${ }^{1}$, Florence Gerin ${ }^{1}$, Jacques Le Gouis², Yvan Moënne-Loccoz¹, Claire PrigentCombaret $^{1^{*}}$

1 Univ Lyon, Université Claude Bernard Lyon 1, CNRS, INRA, VetAgro Sup, UMR5557

Ecologie Microbienne, 43 bd du 11 novembre 1918, F-69622 Villeurbanne, France

${ }^{2}$ GDEC, INRA, UCA, F-63000 Clermont-Ferrand, France

Running title: Wheat breeding and PGPR interaction

(1)

14

16

17

.

(1)

2

(1)

25

${ }^{*}$ Corresponding author: UMR CNRS 5557 Ecologie Microbienne, Université Lyon 1, 43 bd du 11 Novembre 1918, 69622 Villeurbanne cedex, France. Phone +33 47243 13 49. E-mail: claire.prigent-combaret@univ-lyon1.fr 


\section{Abstract}

Plant interactions with Plant Growth-Promoting Rhizobacteria (PGPR) are highly dependent on plant genotype. Modern plant breeding has largely sought to improve crop performance, but with little focus on the optimization of plant $\times$ PGPR interactions. The interactions of the model PGPR strain Pseudomonas kilonensis F113 were therefore compared in 199 ancient and modern wheat genotypes. A reporter system, in which F113 colonization and expression of 2,4-diacetylphloroglucinol biosynthetic genes $(p h l)$ were measured on roots was used to quantify $\mathrm{F} 113 \times$ wheat interactions under gnotobiotic conditions. Thereafter, eight wheat accessions that differed in their ability to interact with F113 were inoculated with F113 and grown in greenhouse in the absence or presence of stress. F113 colonization was linked to improved stress tolerance. Moreover, F113 colonization and phl expression were higher overall on ancient genotypes than modern genotypes. F113 colonization improved wheat performance in the four genotypes that showed the highest level of $p h l$ expression compared to the four genotypes in which phl expression was lowest. Taken together, these data suggest that recent wheat breeding strategies have had a negative impact on the ability of the plants to interact with PGPR.

Keywords : Breeding - DAPG - Fluorescence - Genotypes - PGPR - Phytostimulation Pseudomonas - Wheat 


\section{Introduction}

Agriculture productivity is a major issue, as world population may reach about 9 billion people in 2050 (Gerland et al., 2014; KC \& Lutz, 2017), needing enhanced crop yields in the coming decades. Significant yield improvement was already achieved during the second half of the $20^{\text {th }}$ century, based on the use of chemical inputs including pesticides and mineral fertilizers (Cao, Lu, \& Yu, 2018; Huffman \& Evenson, 2001), drainage/irrigation, and modern breeding to select crop genotypes efficient at taking full advantage of farming inputs (Baranski, 2015; York, Galindo-Castañeda, Schussler, \& Lynch, 2015). However, the consequences of these farming conditions on the interactions between plant roots and the associated bacterial community are not well documented (Engelhard, Hurek, \& Reinhold-Hurek, 2000; Germida \& Siciliano, 2001; Pérez-Jaramillo et al., 2017).

Modern breeding is typically carried out under optimal agronomic conditions, which is likely to limit the potential added-value resulting from beneficial plant-microbe interactions (Sasaki et al., 2010; Schmidt, Bowles, \& Gaudin, 2016; Weese, Heath, Dentinger, \& Lau, 2015). In the case of soil bacteria, this involves Plant Growth-Promoting Rhizobacteria (PGPR), which may stimulate root growth, improve nutrient uptake (Kumar, Maurya, \& Raghuwanshi, 2014; Majeed, Kaleem Abbasi, Hameed, Imran, \& Rahim, 2015), alleviate plant stress (Barnawal et al., 2017; Furlan et al., 2017; García et al., 2017; Pande, Ns, \& Bodhankar, 2016) or protect the plants from pathogens (Díaz Herrera, Grossi, Zawoznik, \& Groppa, 2016; Keshavarz-Tohid et al., 2017). These effects rely on various modes of action, such as increasing nutrient availability, modulating plant hormonal balance (Cassán, Vanderleyden, \& Spaepen, 2014; Saleem, Arshad, Hussain, \& Bhatti, 2007), and/or producing bioactive metabolites (Couillerot et al., 2011; Vacheron et al., 2018). Since these beneficial effects would be of less interest under optimum conditions, it could be that the ability of crop genotypes to interact with PGPR populations, which are naturally present in soil, was not selected for during modern breeding (Morgan, Bending, \& White, 2005; Schmidt et al., 2016; Weese et al., 2015). This type of trait may even have been counter-selected in the case where it involves a cost for the plant. This hypothesis has been evoked on several occasions (Kiers, Palmer, Ives, Bruno, \& Bronstein, 2010; Morgan et al., 2005; West, Kiers, Simms, \& Denison, 2002), but little has been done to test it experimentally with PGPR. In the case of mycorrhizal fungi, some studies reported that modern breeding lead to reduced dependence on mycorrhizal symbiosis (Hetrick, Wilson, \& Cox, 1992; Hetrick, Wilson, \& Cox, 1993), while in a more recent meta-analysis it was concluded that new cultivars were more mycorrhiza-responsive when compared to ancestral genotypes (Lehman, Barto, Powell, \& Rillig, 2012). Given these inconsistent results in the literature, whether or not modern plant breeding has modified the ability of crop plants to interact with plant-beneficial microorganisms remains an open question. If the ability of 
modern genotypes to interact with PGPR was partially or progressively lost, it could provide a basis to understand why the magnitude of PGPR effects differs from one variety to the next (Furlan et al., 2017; Kazi, Deaker, Wilson, Muhammad, \& Trethowan, 2016; Neiverth et al., 2014; Vacheron et al., 2016). It would also mean that ancient genotypes could represent a source of PGPR interaction traits, which may be of potential value for future PGPR-based breeding (Schmidt et al., 2016; Wei \& Jousset, 2017).

The first objective of this work was to test the hypothesis that PGPR interaction ability had not been favored during modern breeding. The second objective was to compare, under stress conditions, PGPR inoculation effects on the growth of wheat genotypes of different PGPR interaction abilities. To address these objectives, a collection of 199 bread wheat accessions, representing world-wide crop genetic diversity and including both ancient genotypes and modern genotypes, was screened for the ability to interact with the model PGPR strain Pseudomonas kilonensis F113. This strain produces 2,4-diacetylphloroglucinol (DAPG), an antimicrobial compound at high concentration (Schnider-Keel et al., 2000; Shanahan, O'Sullivan, Simpson, Glennon, \& O'Gara, 1992) but with auxinic-type rootbranching properties at lower concentration (Brazelton, Pfeufer, Sweat, McSpadden Gardener, \& Coenen, 2008; Vacheron et al., 2018). The pseudomonad stimulates growth of Arabidopsis (Vacheron et al., 2018), maize (Walker et al., 2012) and wheat (Couillerot et al., 2011). Importantly, bacteria closely related to $P$. kilonensis F113 seem widespread in arable soils (Costa et al., 2007; Landa et al., 2002; Mazzola, Funnell, \& Raaijmakers, 2004). An innovative screening method of double fluorescent tagging was developed to measure root colonization by $P$. kilonensis F113 and expression of the DAPG genes phl. Uneven fluorescence levels were obtained depending on the wheat genotypes, modern genotypes interacting less with the PGPR overall. Then, to evaluate the relevance of the screening, wheat accessions showing contrasted results during the screening (including both ancient and modern genotypes) were selected to compare their response to F113 inoculation, under conditions of water stress and nutrient deprivation.

\section{Materials and Methods}

\section{Panel of wheat accessions}

A total of 199 accessions of wheat (Triticum aestivum) were used (Supporting information Table S1). They included (i) the 196CC core-collection (Plessis, Ravel, Bordes, Balfourier, \& Martre, 2013) sub-sampled from the INRA worldwide bread wheat collection of 372 accessions set up by Balfourier et al. (2007), based on field evaluation data (Bordes, Branlard, Oury, Charmet, \& Balfourier, 2008), geographic origin and registration date, (ii) the two reference 
(modern) varieties Hendrix and Skerzzo, and (iii) the genome-sequenced reference (landrace) Chinese Spring. These accessions were chosen to maximize genetic diversity, as indicated by representative genome-wide molecular markers (Balfourier et al., 2007), and they originated from 38 different countries of six continents. Among them, 7 presented major germination problems on agar plate and were removed from the panel, leaving a total of 192 wheat genotypes. The remaining 192 genotypes included 77 ancient genotypes (i.e. 35 landraces, plus 42 old varieties from the 19th century to 1960), as well as 115 modern genotypes (i.e. developed after 1960 and the introduction of Rht-B1b (Rht1) and Rht-D1b (Rht2) alleles from the Japanese variety Norin 10 that conferred reduced gibberellin response; Borlaug, 1968; Borojevic, \& Borojevic, 2005; Peng et al., 1999).

\section{Bacterial strain construction and growth conditions}

For the screening, we performed chromosomal insertion (Koch, Jensen, \& Nybroe, 2001) into P. kilonensis F113 (previously classified as P. fluorescens) of the construct attTn7::miniTn7Gm-Ptac-mCherry for constitutive expression of reporter gene $m$ Cherry (Rochat, Péchy-Tarr, Baehler, Maurhofer, \& Keel, 2010). The gentamicin-resistance cassette was then replaced with a kanamycin-resistance cassette by homologous recombination, using plasmid pCM184 (Marx (not shown). Finally, the derivative P. kilonensis F113-mCherry(Pphl-egfp) was obtained by electroporation (Vacheron et al., 2018) of the gentamicin-resistance plasmid pOT1e carrying a copy of the promoter of the $\mathrm{phl}$ operon fused to the promoterless reporter gene egfp, constructed as described previously (Vacheron et al., 2016).

The inoculum for the screening was prepared by growing strain F113-mCherry(Pphlegfp) for $24 \mathrm{~h}$ in Minimal Medium (MM) broth (García de Salamone, Hynes, \& Nelson, 2001) supplemented with gentamycin $(25 \mu \mathrm{g} / \mathrm{mL})$ and kanamycin $(50 \mu \mathrm{g} / \mathrm{mL})$, at $27^{\circ} \mathrm{C}$ with shaking (180 rpm). For the greenhouse experiment, the wild-type $P$. kilonensis F113 was grown for $24 \mathrm{~h}$ in $\mathrm{MM}$ broth without antibiotics, at $27^{\circ} \mathrm{C}$, with shaking (180 rpm).

\section{Wheat inoculation in the screening experiment}

Wheat seeds were surface-disinfected by consecutive immersion for $1 \mathrm{~min}$ in $70 \%$ ethanol, then for 40 min with shaking $(180 \mathrm{rpm})$ in sodium hypochlorite solution $\left(\mathrm{Na}_{2} \mathrm{CO}_{3} 0.1 \mathrm{~g}, \mathrm{NaCl}\right.$ $3 \mathrm{~g}$ and $\mathrm{NaOH} 0.15 \mathrm{~g}$ in $100 \mathrm{~mL}$ distilled water) supplemented with $10 \%$ commercial bleach (containing $9.6 \%$ of active chlorine) and $0.01 \%$ of Tween $20 \%$. They were washed three times (5 min each) with sterile water, and soaked $60 \mathrm{~min}$ in a last bath of sterile water. For pregermination, disinfected seeds were placed on plates containing sterile agar for plant culture at $8 \mathrm{~g} / \mathrm{L}$ (Agar A7921; Sigma-Aldrich, Saint-Quentin Fallavier, France) and incubated in the dark for $24 \mathrm{~h}$ at $27^{\circ} \mathrm{C}$. The one-day-old seedlings were then transferred in $120 \times 120 \mathrm{~mm}$ 
177 square Petri dishes containing $50 \mathrm{~mL}$ of sterile agar for plant culture (3 seedlings per dish). No nutrient solution was added. The seedlings were inoculated with $50 \mu \mathrm{L}$ of cell suspension containing $5 \times 10^{7} \mathrm{CFU}\left(\mathrm{OD}_{600}\right.$ adjusted to 8.0 , giving $\left.10^{9} \mathrm{CFU} / \mathrm{mL}\right)$ from an overnight culture of F113-mCherry(Pphl-egfp), whose cells had been washed and resuspended in $\mathrm{MgSO}_{4} 10$ $\mathrm{mM}$. For each of the 192 wheat genotypes, 3 seeds were not inoculated and 3 others were inoculated with F113-mCherry(Pphl-egfp). The inoculated seedlings and the controls were placed for seven days in a growth chamber at $21^{\circ} \mathrm{C}$, with a $16 / 8 \mathrm{~h}$ day/night cycle and $60 \%$ hygrometry.

\section{Root sampling and bacterial fluorescence measurements}

To evaluate the ability of each wheat accession to interact with $P$. kilonensis F113, we developed a simplified screening method to enable large-scale, robust comparison of the 192 accessions, based on measurements of bacterial fluorescence. After seven days of growth, the plantlets were removed from agar, each root system was cut in 1-cm fragments and all fragments from a same plant were introduced into a $15-\mathrm{mL}$ Falcon tube containing $3 \mathrm{~mL}$ of $\mathrm{MgSO}_{4} 10 \mathrm{mM}$ and three steel beads ( $5 \mathrm{~mm}$ diameter). The roots were ground for $1 \mathrm{~min}$ (twice) with a FastPrep-24 Classic Instrument (MPbiomedicals, Santa Ana, CA) at maximum speed $(6 \mathrm{~m} / \mathrm{s})$ and room temperature. The biggest plant debris were pelleted by centrifugation for 2 min at 1,500 rpm, and $200 \mu \mathrm{L}$ of each supernatant were transferred in black 96-well plates with a clear bottom. The fluorescence intensities of supernatants were then measured with an Infinite M200 pro microplate reader (Tecan, Männedorf, Switzerland). EGFP level was recorded using an excitation wavelength of $488 \mathrm{~nm}$ and an emission wavelength of $530 \mathrm{~nm}$, and mCherry level using an excitation wavelength of $587 \mathrm{~nm}$ and an emission wavelength of $661 \mathrm{~nm}$. The ratio between green and red fluorescence intensities was computed and used as a proxy for the $p h /$ induction rate. $\mathrm{F} 113$ colonization, $p h /$ expression and $p h /$ induction rate from each individual inoculated plant were used to compute the means for each wheat genotype, after subtracting the mean fluorescence intensity of the three corresponding non-inoculated plantlets.

\section{Screening validation and confocal microscopy observations}

To confirm the screening results, an alternative fluorescence experiment was performed using 20 genotypes that had shown contrasted fluorescence intensities on their roots during the screening (Table 1) and twice as many replicates. To select these genotypes, a PGPR interaction score was calculated for each genotype as the sum of its ranks (i.e. the worst rank was 1 and the best one 192) for F113 colonization, for $p h l$ expression and for $p h l$ induction rate. Seed surface-disinfection and seedling inoculation were done as described above to obtain six plants per genotype. After seven days of growth, each root system was cut in 1-cm 
fragments and all fragments from a same plant were introduced into a 2-mL Eppendorf tube containing $1.5 \mathrm{~mL}$ of $\mathrm{MgSO}_{4} 10 \mathrm{mM}$ (without steel beads). The roots were shaken for $2 \times 5$ min with a TissueLyser (Qiagen, Hilden, Germany) at maximum speed ( $30 \mathrm{~Hz}$ ) and room temperature. Then, the fluorescence of each supernatant was measured, as described above. Root biomass was also determined.

To verify that spectrofluorimeter measurements were truly related to the colonization/expression of the fluorescent F113 derivative, the same 20 genotypes were inoculated (two plantlets per genotype) and grown as described above. For each plant, two root fragments were observed with a confocal microscope (Carl Zeiss, Le Pecq, France), using an excitation laser light of $488 \mathrm{~nm}$ and an emission filter of 504-555 nm for EGFP green fluorescence, and an excitation laser light of $561 \mathrm{~nm}$ and an emission filter 570-636 nm for mCherry red fluorescence, with the same gains for all samples.

\section{Soil pot experiment}

A greenhouse experiment was performed with eight wheat genotypes giving contrasted screening results, i.e. Coronation, Concurrent (ancient genotypes), Amifort and D130-63 (modern genotypes), which showed good F113 interaction results, as well as Jaszaji TF, Odesskaya16 (ancient genotypes), Danubia and Hendrix (modern genotypes), which showed weak interaction results (Table 1). For each genotype, plants from seven pots were inoculated with F113 and subjected to abiotic stress, whereas plants from seven other pots were inoculated with F113 but not subjected to stress. For non-inoculated controls, plants from seven pots were subjected or not to stress for each genotype. Thus, the whole experiment contained 224 pots.

On the first day, wheat seeds were surface-disinfected by stirring them $40 \mathrm{~min}$ in sodium hypochlorite solution (see above), washed three times 5 min with sterile water, and soaked in a last bath of sterile water for $60 \mathrm{~min}$. They were put in 2- $\mathrm{dm}^{3}$ pots containing $1.8 \mathrm{~kg}$ of sieved non-sterile soil (loam, organic matter 5.5\%, $\mathrm{pH}_{\mathrm{H}_{2} \mathrm{O}} 6.0$ ) taken from the topsoil of an arable luvisol located at La Côte Saint-André (France). At first, the soil was watered every two days to maintain a water content of $22 \% \mathrm{w} / \mathrm{w}$ (corresponding to $78 \%$ of the water holding capacity ; El Zemrany et al., 2007). Water content was adjusted by weighing the pots every two days and adding the volume of water that had been lost. Each pot received four seeds, and the number of plants was reduced to three at seven days and then two seven days later. In half the pots, each seed was inoculated with $200 \mu \mathrm{L}$ of a cell suspension of $P$. kilonensis F113 (obtained as described above) containing $2.5 \times 10^{6} \mathrm{CFU}$, whereas seeds in the other half received $200 \mu \mathrm{L}$ of $\mathrm{MgSO}_{4} 10 \mathrm{mM}$ each.

The experiment was run in a greenhouse (randomized block design), with a 16/8 $\mathrm{h}$ day/night cycle at respectively $24 / 20^{\circ} \mathrm{C}$ and $40 / 60 \%$ relative humidity. At 14 days, a combined 
stress of water and nutrient deficiencies was applied to half the non-inoculated pots and half the inoculated pots. To this end, soil was left to dry to $12 \% \mathrm{w} / \mathrm{w}$ water content (corresponding to $43 \%$ water holding capacity) until the end of the experiment in the stress conditions only, and a NPK nutrient solution (Plant-Prod 20-20-20; Plantproducts, Leamington, ON) was used to bring $16 \mathrm{mg} \mathrm{N} /$ plant (8 $\mathrm{mg}$ each on days 14 and 21 ) in the non-stress conditions only.

At the four-leaf stage (i.e. one-month post-inoculation), all the plants were harvested. In each pot, one plantlet was used to evaluate plant growth (i.e. with 7 plants/treatment), after separating root systems from shoots and carefully washing them with water. Shoot height and biomass were measured. Fresh and dry $\left(105^{\circ} \mathrm{C}\right.$ overnight) root biomass were determined, along with root system architecture (number, length, diameter, surface and volume of roots) using WinRhizo image analysis (Regent Instruments, Nepean, ON). The other plantlets were sampled to quantify F113 colonization (using 5 plants/treatment; see below).

\section{Real-time PCR assessment of inoculant colonization}

Root systems were shaken to detach non-adhering soil. They were introduced each into a 50$\mathrm{mL}$ Falcon tube, which was shaken for $15 \mathrm{~min}$, and flash-frozen in liquid nitrogen. The root systems were removed. The soil was pelleted by centrifugation (30 min at 5,100 $\mathrm{g}$ and room temperature), lyophilized for $48 \mathrm{~h}$, weighed, and conserved at $-20^{\circ} \mathrm{C}$. DNA extraction was performed on $300 \mathrm{mg}$ of lyophilized rhizosphere soil transferred into Lysing Matrix E tubes from the FastDNA Spin Kit (MPbiomedicals), according to the manufacturer's instructions, and DNA concentration adjusted to $5 \mathrm{ng} / \mu \mathrm{L}$ for each sample.

$P$. kilonensis $\mathrm{F} 113$ was assessed in rhizosphere soil by real-time PCR, as described by Von Felten et al. (Von Felten, Défago, \& Maurhofer, 2010), using a LC-480 LightCycler and the LightCycler 480 SYBR Green I Master mix (Roche Applied Science, Indianapolis, IN). Melting curve calculation and determination of Tm values were performed using the Lightcycler Software (Roche Applied Science). The $\mathrm{C}_{\mathrm{T}}$ values obtained were normalized using the plasmid Apa9 as internal standard, as described by Couillerot et al. (2010) and Von Felten et al. (2010), in order to standardize DNA extraction efficiencies between rhizosphere samples. The primers amplify a specific region of the F113 strain. In our experiment, the detection limit was 10 copies of the target sequence per reaction. The efficiency was higher than $86 \%$ and the error rate lower than 2\%. Quantities were expressed per $g$ of dry rhizosphere soil and per root system.

\section{Statistics}

Standard errors (SE) were used to show data variability. As screening and quantitative PCR data could not been normalized, comparisons between multiple treatments were made using Kruskal-Wallis rank-sum tests followed by Conover-Iman tests for pairwise comparisons, and comparisons between only two treatments were done using Wilcoxon rank-sum tests. 
Comparison of proportions were made using $\mathrm{Khi}^{2}$ test. For the greenhouse experiment, plant data were normalized using a box-cox transformation and comparisons were made using multiple-factors ANOVA followed with Fisher's LSD tests for pairwise comparisons. All analyses were carried out at $P<0.05$, using XIstat software v2018.4 (Addinsoft, Bordeaux, France).

\section{Results}

\section{Root colonization by $\boldsymbol{P}$. kilonensis F113 was higher on ancient wheat genotypes}

Under the gnotobiotic conditions used for the screening of the 192 wheat genotypes, mCherry fluorescence resulting from F113-mCherry(Pphl-egfp) colonization ranged from $15 \pm$ (SE) 3 for genotype Hendrix to $165 \pm 10$ arbitrary units (AU) for D130-63 at one week (Fig. 1a). F113$m$ Cherry(Pphl-egfp) colonization was higher for ancient genotypes than modern genotypes, based on the two following criteria. First, colonization was significantly higher $(P=0.022)$ for ancient genotypes overall (61 \pm [SE] $3 \mathrm{AU}, \mathrm{n}=77$ ) compared with modern genotypes $(53 \pm 2$ $\mathrm{AU}, \mathrm{n}=115$ ) (Fig. 2a). Second, the 25 genotypes presenting the best $\mathrm{F} 113$ colonization levels corresponded to 15 of 77 ancient genotypes (i.e. 19.5\%) vs only 10 of 115 modern genotypes (i.e. $8.7 \%$ ) (Table 2). Conversely, 6 of the ancient genotypes (7.8\%) vs as many as 19 of the modern genotypes (16.5\%) were part of the 25 least colonized wheat genotypes. Similar trends were observed when considering the 50 best and 50 worst colonized genotypes. Higher colonization of ancient genotypes by F113 was also indicated by the distribution of red fluorescence classes, which showed positive differences in frequency (i.e., the frequency of modern genotypes subtracted from the frequency of ancient genotypes) among the five fluorescence classes above $80 \mathrm{AU}$ (Fig. 3a,c).

When distinguishing between landraces and old varieties $(<1960)$ within the ancient genotype category, it appeared that F113-mCherry(Pphl-egfp) colonization was significantly higher $(P=0.039)$ for old varieties (62 $\pm[S E] 4 \mathrm{AU})$ than for modern genotypes (53 $\pm 2 \mathrm{AU})$, landraces being in an intermediate position (60 $44 \mathrm{AU}$; Supporting information Fig. S1). In addition, there were trends (not significant at $P<0.05$ ) towards (i) higher proportions of landraces $(17.1 \%)$ and old varieties $(21.4 \%)$ than modern genotypes (only $8.7 \%$ ) among the 25 best colonized genotypes, and (ii) lower proportions of landraces (8.6\%) and old varieties $(7.1 \%)$ than modern genotypes (as much as $21.7 \%$ ) among the 25 worst colonized genotypes (Supporting information Table S2). This is also indicated by positive differences in frequencies for both landraces and old varieties (vs modern genotypes) among the five fluorescence classes above $80 \mathrm{AU}$ (Supporting information Fig. S2). 
All 192 genotypes showed egfp fluorescence (i.e. phl expression) upon F113-mCherry(Pphlegfp) inoculation, at levels ranging between $79 \pm$ (SE) 3 for genotype Adular and $1920 \pm 313$ $\mathrm{AU}$ for D130-63 (Fig. 1b). phl expression in F113-mCherry(Pphl-egfp) for the 77 ancient genotypes was significantly higher overall $(P=0.01)(490 \pm[\mathrm{SE}] 25 \mathrm{AU})$ than for the 115 modern genotypes (429 $\pm 20 \mathrm{AU})$ (Fig. 2b).

In addition, the 25 genotypes with the best $p h l$ expression corresponded to 13 of the 77 ancient genotypes (i.e. $16.9 \%$ ) vs only 12 of the 115 modern genotypes (i.e. $10.4 \%$ ), and the difference was statistically significant when considering the 50 genotypes showing the best phl expression, which included 27 of the 77 ancient genotypes (35.1\%) vs only 23 of the 115 modern genotypes $(20 \%)$. Conversely, there was also a trend (not significant at $P<0.05$ ) for a lower prevalence of ancient genotypes (6 of 77 , i.e. $7.8 \%$ ) than modern genotypes (19 of 115 , i.e. $16.5 \%$ ) in the 25 genotypes presenting the worst phl expression (Table 2). Higher phl expression on ancient genotypes is also indicated by the distribution of green fluorescence categories, which showed positive differences in frequency (i.e., the frequency of modern genotypes subtracted from the frequency of ancient genotypes) among the four fluorescence classes above $700 \mathrm{AU}$ (Fig. 3b,d).

Spearman's correlation between F113 root colonization and phl expression was significant $(P<0.001, r=0.85, n=192)$. Accordingly, the level of $p h /$ induction (i.e., the green fluorescence:red fluorescence ratio) was rather similar for a majority of wheat genotypes (Fig. 1c), without any statistical difference between the ancient $(8.0 \pm 0.2)$ and modern $(8.1 \pm 0.2)$ genotype categories (Fig. 2c).

Screening results were validated by alternative fluorescence methodology and confocal microscopy

When the screening was repeated with 20 contrasted genotypes and an alternative fluorescence measurement methodology, the group of 10 genotypes effective at interacting with F113 (hereafter referred to as F113-stimulating genotypes) displayed higher root colonization (210 \pm [SE] 24 vs $102 \pm 12)$ and phl expression (1802 \pm 251 vs $661 \pm 139)$ compared with the group of 10 ineffective genotypes (i.e. non F113-stimulating). In both screenings, red fluorescence and green fluorescence of the 10 F113-stimulating genotypes were respectively about twice and three times as high as for the non F113-stimulating genotypes. Correlation was significant between the two screenings, both for red $(P<0.001, r$ $=0.80, \mathrm{n}=20)$ and green fluorescence levels $(P<0.001, r=0.78, \mathrm{n}=20)$ (Fig. 4).

Confocal microscopy observations confirmed spectrofluorimeter data, in that F113- 
expressing the red and/or the green fluorescence on roots, in comparison with non F113stimulating genotypes (Fig. 5).

\section{F113 colonized roots of all eight selected genotypes in soil}

In non-sterile soil, $P$. kilonensis F113 was recovered by quantitative PCR from inoculated wheat at $2.5 \times 10^{5}$ to $4.2 \times 10^{6}$ copies per root system (Supporting information Fig. S3), whereas it was below the detection limit (i.e. $3.5 \times 10^{4}$ copies per root system) for noninoculated plants. The differences between (i) optimum and stress conditions, (ii) F113stimulating and non F113-stimulating groups of genotypes, (iii) ancient and modern groups of genotypes, or (iv) individual wheat genotypes were not statistically significant. Similar findings were made when expressing results per $\mathrm{g}$ of dry rhizosphere soil (data not shown).

\section{F113 inoculation improved growth of certain wheat genotypes}

Three-factor ANOVA (Supporting information Table S2) indicated that F113 inoculation, overall, enhanced root volume $(+14.8 \%, P<0.01)$, root diameter $(+3.5 \%, P<0.001)$, root number $(+14.9 \%, P<0.001)$ and dry root biomass $(+16.3 \%, P<0.001)$, with a significant inoculation $\times$ genotype interaction for root number and dry root biomass.

Under optimum conditions, the overall inoculation benefits for F113-stimulating vs non F113-stimulating genotypes were higher for all measured parameters when the means [or the medians] of the two groups were compared, with for instance $+47.2 \%[+57.7 \%]$ vs $+17.1 \%$ [-5.6\%] variation for dry root biomass, $+27.8 \%$ [+26.1\%] vs $+18.4 \%$ [+18.1\%] for root number, $+23.2 \%[+21.5 \%]$ vs $+13.0 \%[+14.3 \%]$ for root volume, and $+4.6 \%[+5.7 \%]$ vs $+3.2 \%$ [+3.7\%] for root diameter (Fig. 6a). Inoculation resulted in higher dry root biomass of the two F113-stimulating genotypes Coronation $(+95.8 \%, P<0.01)$ and $\mathrm{D} 130-63(+92.3 \%, P$ $<0.001)$ and the non F113-stimulating genotype Odesskaya16 $(+103.4 \%, P<0.001)$ (Table 3).

Under stress, the overall inoculation benefits for F113-stimulating vs non F113stimulating genotypes were also more important for all measured parameters, with for instance means enhanced by $+36.8 \%$ [and medians enhanced by $+38,3 \%$ ] vs $-1.4 \%$ [ $+2.0 \%$ ] for dry root biomass, $+35.0 \%$ [+44.0\%] vs $+12.1 \%$ [+14.1\%] for root number, $+23.3 \%$ [+23.7 \%] vs $+12.6 \%$ [+13.2\%] for root volume, and $+3.9 \%$ [+4.4\%] vs $+2.8 \%$ [+2.9\%] for root diameter (Fig. 6b). Inoculation of F113-stimulating genotypes enhanced root volume for Coronation (+81.3\%, $P<0.05)$, root diameter for Concurrent $(+11.7 \%, P<0.01)$, root number and root dry biomass for Coronation (respectively $+102.3 \%, P<0.001$ and $+84.6 \%, P<0.01$ ) and D130$63(+101.7 \%, P<0.001$ and $+106.1 \%, P<0.001)$, but it reduced root number $(-50.4 \%, P<$ $0.001)$ and root dry biomass $(-35.3 \%, P<0.05)$ for Amifort, whereas inoculation of non F113stimulating genotypes had no effect (Table 3 ). 


\section{Impact of stress on non-inoculated wheat genotypes}

As $P$. kilonensis F113 was below detection limit in non-inoculated pots (see above), a twofactor ANOVA was performed on the dataset from non-inoculated plants, on the basis that genotype response to stress integrated also the possible contribution of resident plantbeneficial microorganisms (i.e. other than F113). Stress had a significant negative impact on every plant parameter except root length and root number, with a significant stress $\times$ genotype interaction for root diameter and dry root biomass (Supporting information Table S4).

Overall, the impact of stress on F113-stimulating vs non F113-stimulating genotypes on root parameters was respectively $-17.6( \pm 7.3) \%$ vs $-34.8( \pm 2.6) \%$ variation for root volume, $-18.5( \pm 4.6) \%$ vs $-34.8( \pm 5.8) \%$ for fresh root biomass, $+6.9( \pm 12.0) \%$ vs $-19.9( \pm 19.3) \%$ for dry root biomass, and $-9.9( \pm 0.8) \%$ vs $-10.8( \pm 3.6) \%$ for root diameter. For shoot parameters, stress resulted in $-40.2( \pm 5.4) \%$ vs $-40.1( \pm 1.5) \%$ variation for fresh shoot biomass, $-32.5( \pm 6.8) \%$ vs $-34.9( \pm 2.2) \%$ for dry shoot biomass and $-14.8( \pm 2.9) \%$ vs -14.1 $( \pm 1.3) \%$ for shoot height (Fig. 6c). When considering the relative impact of stress, i.e. by computing the stress response index [(replicate performance under stress - mean performance under optimum conditions) / mean performance under optimum conditions], it appeared that the top five performing genotypes under stress conditions included all 4 F113stimulating genotypes versus only 1 of 4 non F113-stimulating genotypes for root length, root number, dry root biomass and root volume.

At the scale of individual F113-stimulating genotypes, the impact of stress was significant on root diameter (for all 8 genotypes), fresh shoot biomass and shoot height (for all genotypes but Coronation), and dry shoot biomass (for Concurrent and Amifort) (Supporting information Table S5). For individual non F113-stimulating genotypes, the effect of stress was significant on root volume, fresh and dry root biomass (for Hendrix and Danubia), root diameter (for all but Danubia), fresh shoot biomass and shoot height (for all four genotypes), and dry shoot biomass (for Jaszaji TF and Hendrix).

\section{Discussion}

Crop breeding has resulted in the development of thousands of genotypes, which show contrasted agro-morphological and metabolic features (Berry, Kendall, Rutterford, Orford, \& Griffiths, 2015; Beyer, Daba, Tyagi, Bockelman, \& Brown-Guedira, 2018; Gotti et al., 2018; Shaposhnikov et al., 2016; Siddique, Belford, \& Tennant, 1990; York et al., 2015; Zhang et al., 2013), as well as contrasted stress response patterns (Esmail, Eldessouky, Mahfouz, \& ElDemardash, 2016; Khakwani, Dennett, \& Munir, 2011; Ramshini, Mirzazadeh, Moghaddam, \& Amiri, 2016). Crop genotypes can also differ in their ability to recruit soil bacteria (Bouffaud et 
al., 2012), induce gene expression in rhizobacteria (Notz et al., 2001; Vacheron et al., 2016), and respond to PGPR inoculation (Sasaki et al., 2010; Vacheron et al., 2016). The impact of breeding on PGPR $\times$ crop interactions is an important issue, but there have been very few studies on this. When investigated, it was done by using a very small number of genotypes considering the extent of crop diversity (Furlan et al., 2017; Kazi et al., 2016; Neiverth et al., 2014).

Here, we compared wheat genotypes resulting from modern breeding efforts (i.e. post1960 ) with ancient wheat genotypes, based on their ability to interact with the model PGPR $P$. kilonensis F113. This approach was relevant since (i) this type of bacterium may occur naturally in various types of cultivated soils (Costa et al., 2007; Landa et al., 2002; Mazzola et al., 2004), and (ii) strain F113 can interact with different crop species and cultivars, but with differences from one crop cultivar to the next (Vacheron et al., 2016). To cope with the extent of wheat diversity, almost 200 genotypes representative of this diversity were considered, which signifies an unprecedented scale for this type of work. To obtain robust screening results, we had to rely on a simplified experimental design, which proved effective to compare wheat genotypes (but which could not integrate the complexity of the rhizosphere ecosystem). It required the development of a novel methodology, based on the use of reporter gene fusions and the assessment of autofluorescent proteins. Importantly, this approach enabled the monitoring of both colonization and gene expression of the inoculant on roots. The results of the screening were validated using a subset of 20 genotypes, based on an alternative fluorescence measurement protocol (and twice as many replicates) as well as direct confocal microscopy observations.

Screening results showed that root colonization by F113 was higher on ancient genotypes than modern ones. This type of finding was not found in the pot experiment, as the difference in $\mathrm{F} 113$ root colonization between the 8 wheat genotypes was not significant. This might be due to the small number of genotypes that could be compared in the pot experiment. The discrepancy may result also from the contrasts in growth matrix (mineral soil vs agar), wheat development stage (Di Salvo, Ferrando, Fernández-Scavino, \& García de Salamone, 2018), and/or presence in the soil only of an indigenous microbiota (Thomas \& Sekhar, 2016; Vacheron et al., 2018). As for root colonization, phl expression was higher for ancient genotypes than modern ones. There was a strong correlation between root colonization and phl expression, and indeed the ratio between both measurements (i.e. phl induction ratio) did not fluctuate as much between genotypes, pointing to a rather constitutive $\mathrm{phl}$ expression in F113 on most wheat genotypes. This is consistent with previous observations on the regulation of phl expression in (other) Pseudomonas strains (Paulin et al., 2009; Schnider-Keel et al., 2000). It might be explained by (i) ecological conditions on roots during the short duration of the screening assay, and/or (ii) the production by a majority of wheat genotypes of similar key 
exudate compounds controlling phl expression (De Werra, Baehler, Huser, Keel, \& Maurhofer, 2008; Duffy, Défago, \& Duffy, 1999; Shanahan et al., 1992).

In this work, the screening focused on bacterial root colonization and gene induction. To determine whether PGPR interaction ability could translate into enhanced plant performance, a greenhouse pot experiment was carried out with four F113-stimulating genotypes and four non F113-stimulating genotypes, whose status had been determined in the gnotobiotic screening. Contrasted phytostimulation effects between wheat genotypes may be expected based on (i) previous studies on plant $\times$ bacteria interactions (Kazi et al., 2016), and (ii) the ability of DAPG (like auxins) to increase root system branching (Brazelton et al., 2008). Indeed, inoculation with P. kilonensis F113 enhanced plant performance for 2 of 4 F113stimulating genotypes and 1 of 4 non F113-stimulating genotypes under optimum conditions, versus as many as 4 of 4 F113-stimulating genotypes but none of the 4 non F113-stimulating genotypes under stress (Table 3 ). This shows the ability of F113 to enhance growth of certain host genotypes under stress conditions, as previously described for maize (Vacheron et al., 2016), and strongly suggests an impact of stress on wheat $\times$ F113 interactions. Differences in interaction specificity/affinity between plant genotypes and inoculated bacteria might entail differences in inoculant survival (which was not the case here) or in inoculant effects on host transcriptional and metabolic profiles (Chamam, Wisniewski-Dyé, Comte, Bertrand, \& PrigentCombaret, 2015; Drogue et al., 2014). It had been reported that DAPG could have phytotoxic effect on roots at high concentration (Brazelton et al., 2008; Keel et al., 1992), but this was unlikely as inoculation did not have any negative effect on the 8 genotypes under optimum conditions. F113 inoculation may also trigger changes in the root microbial community (Walsh et al., 2003), but it is unknown whether this impact could be plant genotype-dependent, although it is likely to be the case (Andreote, Da Rocha, Araújo, Azevedo, \& Van Overbeek, 2010). Here, in the absence of inoculation, the top performing genotypes in terms of stress response index included mainly F113-stimulating genotypes, which raises the possibility that other (resident) plant-beneficial microorganisms could have contributed to stress alleviation. In maize, cultivar PR37Y15 responded to the PGPR P. kilonensis F113 as well as to various PGPR inoculants (Walker et al., 2012), whereas cultivar DK315 did not respond (Walker et al., 2013).

Our results suggest that the search for high-yield wheat cultivars under agronomicallyoptimized conditions, which caused genetic diversity loss (Bonnin, Bonneuil, Goffaux, Montalent, \& Goldringer, 2014; Roussel, Leisova, Exbrayat, Stehno, \& Balfourier, 2005; Winfield et al., 2018), did not favor the maintenance of plant genes promoting PGPR interactions. Modern genotypes are mostly dwarf or semi-dwarf varieties because of the introduction of dwarfism Rht-B1b and Rht-D1b alleles in the 1960's, by CIMMYT (International Maize and Wheat Improvement Center) in Mexico and thereafter during wheat breeding 
programs in other parts of the world (Borlaug, 1968; Lumpkin, 2015; Subira et al., 2016). These genes confer a reduced response to gibberellic acid. This prevents stem lodging that arose in response to the increase in size and biomass of the spike, because of the massive fertilization of fields implemented after the Second World War (Berry et al., 2015; Borojevic, \& Borojevic, 2005). Modern genotypes may differ from ancient genotypes in terms of metabolic composition (Di Loreto et al., 2018; Gotti et al., 2018; Iannucci, Fragasso, Beleggia, Nigro, \& Papa, 2017; Shaposhnikov et al., 2016) and root architecture (Beyer et al., 2018; Horst, Abdou, \& Wiesler, 1993; Pour-Aboughadareh, Ahmadi, Mehrabi, Moghaddam, \& Etminan, 2017; Shaposhnikov et al., 2016; Siddique et al., 1990), which is likely to affect plant $\times$ PGPR interactions. Against this background, however, results also revealed that (i) many ancient genotypes were not effective for interaction (especially colonization) with P. kilonensis F113, while (ii) interaction effectiveness with F113 had been maintained in a significant proportion of modern wheat genotypes. Yet, this work was performed with one Pseudomonas model PGPR only, and it would be valuable to check, in further studies, whether these genotypes would respond in the same way to other PGPR species or to plant-beneficial fungi. On one hand, breeding strategies may need to be reassessed to give further consideration to roots and below-ground processes (Den Herder et al., 2010), including the interactions with beneficial microorganisms (Gopal \& Gupta, 2016; Wissuwa, Mazzola, \& Picard, 2009). On the other hand, it may be wise to identify PGPR-friendly genotypes among the current and future high-yield wheat cultivars available to farmers, and the current approach could be expanded to take into account the interaction specificities of other types of PGPR as well as beneficial fungi.

\section{Acknowledgments}

This work was funded by the ANR BacterBlé (ANR-14-CE19-0017). We thank the Center of Biological Resources of INRA GDEC for supply of wheat seeds, Biogemma for technical advice, the Serre and the Centre Technologique des Microstructures platforms of FR BioEnviS for technical support, and team members for help with wheat harvest.

\section{Author contribution}

Conceptualization J.V., J.L.G., C.P.C. and Y.M.L.; Methodology, J.V., J.L.G., Y.M.L. and C.P.C.; Investigation, J.V., F.G., Y.M.L. and C.P.C.; Formal Analysis, J.V.; Writing - Original Draft, J.V., Y.M.L. and C.P.C.; Writing - Review \& Editing, J.V., J.L.G., Y.M.L. and C.P.C.; Funding Acquisition J.L.G., C.P.C. and Y.M.L.; Resources, J.L.G. 
545

546

547

548

549

550

551

552

553

554

555

556

557

558

559

560

561

562

563

564

565

566

567

568

569

570

571

572

573

574

575

576

577

578

\section{Conflict of interest}

The authors declare that they have no conflict of interest

\section{References}

Andreote, F. D., Da Rocha, U. N., Araújo, W. L., Azevedo, J. L., \& Van Overbeek, L. S. (2010). Effect of bacterial inoculation, plant genotype and developmental stage on rootassociated and endophytic bacterial communities in potato (Solanum tuberosum). Antonie van Leeuwenhoek, 97(4), 389-399. https://doi.org/10.1007/s10482-010-9421-9

Balfourier, F., Roussel, V., Strelchenko, P., Exbrayat-Vinson, F., Sourdille, P., Boutet, G., ... Charmet, G. (2007). A worldwide bread wheat core collection arrayed in a 384-well plate. Theoretical and Applied Genetics, 114(7), 1265-1275. https://doi.org/10.1007/s00122007-0517-1

Baranski, M. R. (2015). Wide adaptation of Green Revolution wheat: International roots and the Indian context of a new plant breeding ideal, 1960-1970. Studies in History and Philosophy of Science Part C, 50, 41-50. https://doi.org/10.1016/j.shpsc.2015.01.004

Barnawal, D., Bharti, N., Pandey, S. S., Pandey, A., Chanotiya, C. S., \& Kalra, A. (2017). Plant growth-promoting rhizobacteria enhance wheat salt and drought stress tolerance by altering endogenous phytohormone levels and TaCTR1/TaDREB2 expression. Physiologia Plantarum, 161(4), 502-514. https://doi.org/10.1111/ppl.12614

Berry, P. M., Kendall, S., Rutterford, Z., Orford, S., \& Griffiths, S. (2015). Historical analysis of the effects of breeding on the height of winter wheat (Triticum aestivum) and consequences for lodging. Euphytica, 203(2), 375-383. https://doi.org/10.1007/s10681014-1286-y

Beyer, S., Daba, S., Tyagi, P., Bockelman, H., Brown-Guedira, G., IWGSC, \& Mohammadi, M. (2019). Loci and candidate genes controlling root traits in wheat seedlings - a wheat root GWAS. Functional \& Integrative Genomics, 19(1), 91-107. https://doi.org/10.1007/s10142-018-0630-z

Bonnin, I., Bonneuil, C., Goffaux, R., Montalent, P., \& Goldringer, I. (2014). Explaining the decrease in the genetic diversity of wheat in France over the 20th century. Agriculture, Ecosystems and Environment, 195, 183-192. https://doi.org/10.1016/j.agee.2014.06.003

Bordes, J., Branlard, G., Oury, F. X., Charmet, G., \& Balfourier, F. (2008). Agronomic characteristics, grain quality and flour rheology of 372 bread wheats in a worldwide core 


$$
\text { collection. Journal of Cereal Science, 48(3), 569-579. }
$$
https://doi.org/10.1016/j.jcs.2008.05.005

Borlaug, O. (1968). Wheat breeding and its impact on world food supply. In Proceedings of the Third International Wheat Genetics Symposium, pp. 1-36. Australian Academy of Science, Canberra

Borojevic, K., \& Borojevic, K. (2005). The transfer and history of "Reduced Height Genes" (Rht) in wheat from Japan to Europe. Journal of Heredity, 96(4), 455-459. doi:10.1093/jhered/esi06

Bouffaud, M. L., Kyselková, M., Gouesnard, B., Grundmann, G., Muller, D., \& Moënne-Loccoz, Y. (2012). Is diversification history of maize influencing selection of soil bacteria by roots? Molecular Ecology, 21(1), 195-206. https://doi.org/10.1111/j.1365-294X.2011.05359.x

Brazelton, J. N., Pfeufer, E. E., Sweat, T. A., McSpadden Gardener, B., \& Coenen, C. (2008). 2,4-Diacetylphloroglucinol alters plant root development. Molecular Plant-Microbe Interactions, 21(10), 1349-1358. https://doi.org/10.1094/MPMI-21-10-1349

Cao, P., Lu, C., \& Yu, Z. (2018). Historical nitrogen fertilizer use in agricultural ecosystems of the contiguous United States during 1850-2015: Application rate, timing, and fertilizer types. Earth System Science Data, 10(2), 969-984. https://doi.org/10.5194/essd-10-9692018

Cassán, F., Vanderleyden, J., \& Spaepen, S. (2014). Physiological and agronomical aspects of phytohormone production by model Plant-Growth-Promoting Rhizobacteria (PGPR) belonging to the genus Azospirillum. Journal of Plant Growth Regulation, 33(2), 440-459. https://doi.org/10.1007/s00344-013-9362-4

Chamam, A., Wisniewski-Dyé, F., Comte, G., Bertrand, C., \& Prigent-Combaret, C. (2015). Differential responses of Oryza sativa secondary metabolism to biotic interactions with cooperative, commensal and phytopathogenic bacteria. Planta, 242(6), 1439-1452. https://doi.org/10.1007/s00425-015-2382-5

Costa, R., Gomes, N. C. M., Krögerrecklenfort, E., Opelt, K., Berg, G., \& Smalla, K. (2007). Pseudomonas community structure and antagonistic potential in the rhizosphere: Insights gained by combining phylogenetic and functional gene-based analyses. Environmental Microbiology, 9(9), 2260-2273. https://doi.org/10.1111/j.1462-2920.2007.01340.x

Couillerot, O., Bouffaud, M. L., Baudoin, E., Muller, D., Caballero-Mellado, J., \& MoënneLoccoz, Y. (2010). Development of a real-time PCR method to quantify the PGPR strain Azospirillum lipoferum CRT1 on maize seedlings. Soil Biology and Biochemistry, 42(12), 2298-2305. https://doi.org/10.1016/j.soilbio.2010.09.003 
Couillerot, O., Combes-Meynet, E., Pothier, J. F., Bellvert, F., Challita, E., Poirier, M. A., ... Prigent-Combaret, C. (2011). The role of the antimicrobial compound 2,4diacetylphloroglucinol in the impact of biocontrol Pseudomonas fluorescens F113 on Azospirillum brasilense phytostimulators. Microbiology, 157(6), 1694-1705. https://doi.org/10.1099/mic.0.043943-0

De Werra, P., Baehler, E., Huser, A., Keel, C., \& Maurhofer, M. (2008). Detection of plantmodulated alterations in antifungal gene expression in Pseudomonas fluorescens CHAO on roots by flow cytometry. Applied and Environmental Microbiology, 74(5), 1339-1349. https://doi.org/10.1128/AEM.02126-07

Den Herder, G., Van Isterdael, G., Beeckman, T., \& De Smet, I. (2010). The roots of a new green revolution. Trends in Plant Science, 15(11), 600-607. https://doi.org/10.1016/j.tplants.2010.08.009

Di Loreto, A., Bosi, S., Montero, L., Bregola, V., Marotti, I., Sferrazza, R. E., ... Cifuentes, A. (2018). Determination of phenolic compounds in ancient and modern durum wheat genotypes. Electrophoresis, 39(15), 2001-2010. https://doi.org/10.1002/elps.201700439

Di Salvo, L. P., Ferrando, L., Fernández-Scavino, A., \& García de Salamone, I. E. (2018). Microorganisms reveal what plants do not: wheat growth and rhizosphere microbial communities after Azospirillum brasilense inoculation and nitrogen fertilization under field conditions. Plant and Soil, 424(1-2), 405-417. https://doi.org/10.1007/s11104-017-35487

Díaz Herrera, S., Grossi, C., Zawoznik, M., \& Groppa, M. D. (2016). Wheat seeds harbour bacterial endophytes with potential as plant growth promoters and biocontrol agents of Fusarium graminearum. Microbiological Research, 186-187, 37-43. https://doi.org/10.1016/j.micres.2016.03.002

Drogue, B., Sanguin, H., Chamam, A., Mozar, M., Llauro, C., Panaud, O., ... Wisniewski-Dyé, F. (2014). Plant root transcriptome profiling reveals a strain-dependent response during Azospirillum-rice cooperation. Frontiers in Plant Science, 5(November), 1-14. https://doi.org/10.3389/fpls.2014.00607

Duffy, B. K., Défago, G., \& Duffy, B. K. (1999). Environmental factors modulating antibiotic and siderophore biosynthesis by Pseudomonas fluorescens biocontrol strains. Applied and Environmental Microbiology, 65(6), 2429-2438

El Zemrany, H., Czarnes, S., Hallett, P. D., Alamercery, S., Bally, R., \& Jocteur Monrozier, L. (2007). Early changes in root characteristics of maize (Zea mays) following seed inoculation with the PGPR Azospirillum lipoferum CRT1. Plant and Soil, 291(1-2), 109- 
Engelhard, M., Hurek, T., \& Reinhold-Hurek, B. (2000). Preferential occurrence of diazotrophic endophytes, Azoarcus spp., in wild rice species and land races of Oryza sativa in comparison with modern races. Environmental Microbiology, 2(2), 131-141. https://doi.org/10.1046/j.1462-2920.2000.00078.x

Esmail, R. M., Eldessouky, S. E. I., Mahfouz, S. A., \& El-Demardash, I. S. (2016). Evaluation of new bread wheat lines (Triticum aestivum L.) under normal and water stress conditions. International Journal of ChemTech Research, 9(05), 89-99.

Furlan, F., Saatkamp, K., Volpiano, C. G., De Assis Franco, F., Dos Santos, M. F., Vendruscolo, E. C. G., ... Da Costa, A. C. T. (2017). Plant growth-promoting bacteria effect in withstanding drought in wheat cultivars. Scientia Agraria, 18(2), 104-113. https://doi.org/10.5380/rsa.v18i2.51385

García de Salamone, I. E., Hynes, R. K., \& Nelson, L. M. (2001). Cytokinin production by plant growth promoting rhizobacteria and selected mutants. Canadian Journal of Microbiology, 47(5), 404-411. https://doi.org/10.1139/cjm-47-5-404

García, J. E., Maroniche, G., Creus, C., Suárez-Rodríguez, R., Ramirez-Trujillo, J. A., \& Groppa, M. D. (2017). In vitro PGPR properties and osmotic tolerance of different Azospirillum native strains and their effects on growth of maize under drought stress. Microbiological Research, 202(April), 21-29. https://doi.org/10.1016/j.micres.2017.04.007

Gerland, P., Raftery, A. E., Ševčíková, H., Li, N., Gu, D., Spoorenberg, T., ... Wilmoth, J. (2014). World population stabilization unlikely this century. Science, 346(6206), 234 LP 237. Retrieved from http://science.sciencemag.org/content/346/6206/234.abstract

Germida, J. J., \& Siciliano, S. D. (2001). Taxonomic diversity of bacteria associated with the roots of modern, recent and ancient wheat cultivars. Biology and Fertility of Soils, 33(5), 410-415. https://doi.org/10.1007/s003740100343

Gopal, M., \& Gupta, A. (2016). Microbiome selection could spur next-generation plant breeding strategies. Frontiers in Microbiology, 7(December), 1-10. https://doi.org/10.3389/fmicb.2016.01971

Gotti, R., Amadesi, E., Fiori, J., Bosi, S., Bregola, V., Marotti, I., \& Dinelli, G. (2018). Differentiation of modern and ancient varieties of common wheat by quantitative capillary electrophoretic profile of phenolic acids. Journal of Chromatography A, 1532, 208-215. https://doi.org/10.1016/j.chroma.2017.11.058

Hetrick, B. A. D., Wilson, G. W. T., \& Cox, T. S. (1992). Mycorrhizal dependence of modern 
wheat varieties, landraces, and ancestors. Canadian Journal of Botany, 70(10), 20322040. https://doi.org/10.1139/b92-253

Hetrick, B. A. D., Wilson, G. W. T., \& Cox, T. S. (1993). Mycorrhizal dependence of modern wheat varieties, landraces, and ancestors: a synthesis. Canadian Journal of Botany, 71(3), 512-518. https://doi.org/10.1139/b93-056

Horst, W. J., Abdou, M., \& Wiesler, F. (1993). Genotypic differences in phosphorus efficiency of wheat. Plant and Soil, 155-156(1), 293-296. https://doi.org/10.1007/BF00025040

Huffman, W. E., \& Evenson, R. E. (2001). Structural and productivity change in US agriculture, 1950-1982. Agricultural Economics, 24(2), 127-147. https://doi.org/10.1016/S01695150(00)00065-7

lannucci, A., Fragasso, M., Beleggia, R., Nigro, F., \& Papa, R. (2017). Evolution of the crop rhizosphere: Impact of domestication on root exudates in tetraploid wheat (Triticum turgidum L.). Frontiers in Plant Science, 8(December). https://doi.org/10.3389/fpls.2017.02124

Kazi, N., Deaker, R., Wilson, N., Muhammad, K., \& Trethowan, R. (2016). The response of wheat genotypes to inoculation with Azospirillum brasilense in the field. Field Crops Research, 196, 368-378. https://doi.org/10.1016/j.fcr.2016.07.012

KC, S., \& Lutz, W. (2017). The human core of the shared socioeconomic pathways: Population scenarios by age, sex and level of education for all countries to 2100 . Global Environmental Change, 42, 181-192. https://doi.org/10.1016/j.gloenvcha.2014.06.004

Keel, C., Schnider, U., Maurhofer, M., Voisard, C., Laville, J., Burger, U., ... Défago, G. (1992). Suppression of root disease by Pseudomonas fluorescens CHAO: Importance of the bacterial secondary metabolite 2,4-diacetylphloroglucinol. Molecular Plant-Microbe Interactions, 5, 4-13. https://doi.org/10.1094/MPMI-5-004

Keshavarz-Tohid, V., Taheri, P., Muller, D., Prigent-Combaret, C., Vacheron, J., Taghavi, S. M., ... Moënne-Loccoz, Y. (2017). Phylogenetic diversity and antagonistic traits of root and rhizosphere pseudomonads of bean from Iran for controlling Rhizoctonia solani. Research in Microbiology, 168(8), 760-772. https://doi.org/10.1016/j.resmic.2017.08.002

Khakwani, A. A., Dennett, M. D., \& Munir, M. (2011). Drought tolerance screening of wheat varieties by inducing water stress conditions. Songklanakarin Journal of Science and Technology, 33(2), 135-142. https://doi.org/10.1016/j.fcr.2007.04.007

Kiers, E., Palmer, T. M., Ives, A. R., Bruno, J. F., \& Bronstein, J. L. (2010). Mutualisms in a changing world: An evolutionary perspective. Ecology Letters, 13(12), 1459-1474. https://doi.org/10.1111/j.1461-0248.2010.01538.x 
Koch, B., Jensen, L. E., \& Nybroe, O. (2001). A panel of Tn7-based vectors for insertion of the gfp marker gene or for delivery of cloned DNA into Gram-negative bacteria at a neutral chromosomal site. Journal of Microbiological Methods, 45(3), 187-195. https://doi.org/10.1016/S0167-7012(01)00246-9

Kumar, A., Maurya, B. R., \& Raghuwanshi, R. (2014). Isolation and characterization of PGPR and their effect on growth, yield and nutrient content in wheat (Triticum aestivum L.). Biocatalysis and Agricultural Biotechnology, 3(4), 121-128. https://doi.org/10.1016/j.bcab.2014.08.003

Landa, B. B., Mavrodi, O. V, Raaijmakers, J. M., McSpadden Gardener, B. B., Thomashow, L. S., \& Weller, D. M. (2002). Differential ability of genotypes of Pseudomonas fluorescens strains to colonize the roots of pea plants. Applied and Environmental Microbiology, 68(7), 3226-3237. https://doi.org/10.1128/AEM.68.7.3226

Lehman, A., Barto, E. K., Powell, J. R., \& Rillig, M. C. (2012). Mycorrhizal responsiveness trends in annual crop plants and their wild relatives-a meta-analysis on studies from 1981 to 2010. Plant and Soil, 355, 231-250. https://doi.org/10.1007/s11104-011-1095-1

Lumpkin, T.A. (2015). How a gene from Japan revolutionized the world of wheat: CIMMYT's quest for combining genes to mitigate threats to global food security. In Advances in wheat genetics: from genome to field. (eds. Y. Ogihara, S. Takumi, H. Handa), pp 13-20. Springer, Tokyo

Majeed, A., Kaleem Abbasi, M., Hameed, S., Imran, A., \& Rahim, N. (2015). Isolation and characterization of plant growth-promoting rhizobacteria from wheat rhizosphere and their effect on plant growth promotion. Frontiers in Microbiology, 6(March), 1-10. https://doi.org/10.3389/fmicb.2015.00198

Marx, C. J., \& Lidstrom, M. E. (2002). Broad-host-range cre-lox system for antibiotic marker recycling in Gram-negative bacteria. BioTechniques, 33(5), 1062-1067

Mazzola, M., Funnell, D. L., \& Raaijmakers, J. M. (2004). Wheat cultivar-specific selection of 2,4-diacetylphloroglucinol-producing fluorescent $P$ seudomonas species from resident soil populations. Microbial Ecology, 48(3), 338-348. https://doi.org/10.1007/s00248-0031067-y

Morgan, J. A. W., Bending, G. D., \& White, P. J. (2005). Biological costs and benefits to plantmicrobe interactions in the rhizosphere. Journal of Experimental Botany, 56(417), 17291739. https://doi.org/10.1093/jxb/eri205

Neiverth, A., Delai, S., Garcia, D. M., Saatkamp, K., de Souza, E. M., Pedrosa, F. de O., ... da Costa, A. C. T. (2014). Performance of different wheat genotypes inoculated with the plant 
growth promoting bacterium Herbaspirillum seropedicae. European Journal of Soil Biology, 64, 1-5. https://doi.org/10.1016/j.ejsobi.2014.07.001

Notz, R., Maurhofer, M., Schnider-Keel, U., Duffy, B., Haas, D., \& Défago, G. (2001). Biotic factors affecting expression of the 2,4-diacetylphloroglucinol biosynthesis gene phIA in Pseudomonas fluorescens biocontrol strain $\mathrm{CHAO}$ in the rhizosphere. Phytopathology, 91(9), 873-881. https://doi.org/10.1094/PHYTO.2001.91.9.873

Pande, A. M., Ns, K., \& Bodhankar, M. G. (2016). Effect of PGPR with ACC- deaminase activity on growth performance of wheat cultivated under stress conditions. International Journal of Applied Research, 2(1), 723-726

Paulin, M. M., Novinscak, A., St-Arnaud, M., Goyer, C., Decoste, N. J., Privé, J. P., ... Filion, M. (2009). Transcriptional activity of antifungal metabolite-encoding genes phID and hcnBC in Pseudomonas spp. using qRT-PCR. FEMS Microbiology Ecology, 68(2), 212222. https://doi.org/10.1111/j.1574-6941.2009.00669.x

Peng, J., Richards, D. E., Hartley, N. M., Murphy, G. P., Devos, K. M., Flintham, J. E., ..., Harberd, N. P. (1999). 'Green revolution' genes encode mutant gibberellin response modulators. Nature, 400(6741), 256-261. https://doi.org/10.1038/22307

Pérez-Jaramillo, J. E., Carrion, V. J., Bosse, M., Ferrao, L. F. V, de Hollander, M., Garcia, A. A. F., ... Raaijmakers, J. M. (2017). Linking rhizosphere microbiome composition of wild and domesticated Phaseolus vulgaris to genotypic and root phenotypic traits. ISME Journal, 11, 2244-2257. https://doi.org/10.1038/ismej.2017.85

Plessis, A., Ravel, C., Bordes, J., Balfourier, F., \& Martre, P. (2013). Association study of wheat grain protein composition reveals that gliadin and glutenin composition are transregulated by different chromosome regions. Journal of Experimental Botany, 64(12), 3627-3644. https://doi.org/10.1093/jxb/ert188

Pour-Aboughadareh, A., Ahmadi, J., Mehrabi, A., Moghaddam, M., \& Etminan, A. (2017). Evaluation of diversity in wild relatives of wheat. Journal of Agricultural Science and Technology, 19(4), 943-956

Ramshini, H., Mirzazadeh, T., Moghaddam, M. E., \& Amiri, R. (2016). Comparison of old and new wheat cultivars in Iran by measuring germination related traits, osmotic tolerance and ISSR diversity. Physiology and Molecular Biology of Plants, 22(3), 391-398. https://doi.org/10.1007/s12298-016-0372-0

Rochat, L., Péchy-Tarr, M., Baehler, E., Maurhofer, M., \& Keel, C. (2010). Combination of fluorescent reporters for simultaneous monitoring of root colonization and antifungal gene expression by a biocontrol pseudomonad on cereals with flow cytometry. Molecular Plant- 
Microbe Interactions, 23(7), 949-961. https://doi.org/10.1094/MPMI-23-7-0949

Roussel, V., Leisova, L., Exbrayat, F., Stehno, Z., \& Balfourier, F. (2005). SSR allelic diversity changes in 480 European bread wheat varieties released from 1840 to 2000 . Theoretical and Applied Genetics, 111(1), 162-170. https://doi.org/10.1007/s00122-005-2014-8

Saleem, M., Arshad, M., Hussain, S., \& Bhatti, A. S. (2007). Perspective of plant growth promoting rhizobacteria (PGPR) containing ACC deaminase in stress agriculture. Journal of Industrial Microbiology and Biotechnology, 34(10), 635-648. https://doi.org/10.1007/s10295-007-0240-6

Sasaki, K., Ikeda, S., Eda, S., Mitsui, H., Hanzawa, E., Kisara, C., ... Sato, T. (2010). Impact of plant genotype and nitrogen level on rice growth response to inoculation with Azospirillum sp. strain B510 under paddy field conditions. Soil Science and Plant Nutrition, 56(4), 636-644. https://doi.org/10.1111/j.1747-0765.2010.00499.x

Schmidt, J. E., Bowles, T. M., \& Gaudin, A. C. M. (2016). Using ancient traits to convert soil health into crop yield: Impact of selection on maize root and rhizosphere function. Frontiers in Plant Science, 7(March), 1-11. https://doi.org/10.3389/fpls.2016.00373

Schnider-Keel, U., Seematter, A., Maurhofer, M., Blumer, C., Duffy, B., Gigot-Bonnefoy, C., ... Keel, C. (2000). Autoinduction of 2, 4-diacetylphloroglucinol biosynthesis in the biocontrol agent Pseudomonas fluorescens $\mathrm{CHAO}$ and repression by the bacterial metabolites salicylate and pyoluteorin. Journal of Bacteriology, 182(5), 1215-1225. Retrieved from http://jb.asm.org/content/182/5/1215.short

Shanahan, P., O'Sullivan, D. J., Simpson, P., Glennon, J. D., \& O'Gara, F. (1992). Isolation of 2,4-diacetylphloroglucinol from a fluorescent pseudomonad and investigation of physiological parameters influencing its production. Applied and Environmental Microbiology, 58(1), 353-358

Shaposhnikov, A., Morgounov, A., Akin, B., Makarova, N., Belimov, A., \& Tikhonovich, I. (2016). Comparative characteristics of root systems and root exudation of synthetic, landrace and modern wheat varieties. Agricultural Biology, 51(1), 68-78. https://doi.org/10.15389/agrobiology.2016.1.68rus

Siddique, K. H. M., Belford, R. K., \& Tennant, D. (1990). Root:shoot ratios of old and modern, tall and semi-dwarf wheats in a mediterranean environment. Plant and Soil, 121(1), 8998. https://doi.org/10.1007/BF00013101

Subira, J., Ammar, K., Álvaro, F., García del Moral, L. F., Dreisigacker, S., \& Royo, C. (2016). Changes in durum wheat root and aerial biomass caused by the introduction of the RhtB1b dwarfing allele and their effects on yield formation. Plant and Soil, 403(1-2), 291- 
Thomas, P., \& Sekhar, A. C. (2016). Effects due to rhizospheric soil application of an antagonistic bacterial endophyte on native bacterial community and its survival in soil: A case study with Pseudomonas aeruginosa from banana. Frontiers in Microbiology, 7(April), 1-16. https://doi.org/10.3389/fmicb.2016.00493

Vacheron, J., Combes-Meynet, E., Walker, V., Gouesnard, B., Muller, D., Moënne-Loccoz, Y., \& Prigent-Combaret, C. (2016). Expression on roots and contribution to maize phytostimulation of 1-aminocyclopropane-1-decarboxylate deaminase gene acdS in Pseudomonas fluorescens F113. Plant and Soil, 407(1-2), 187-202. https://doi.org/10.1007/s11104-016-2907-0

Vacheron, J., Desbrosses, G., Renoud, S., Padilla, R., Walker, V., Muller, D., \& Prigent-

Von Felten, A., Défago, G., \& Maurhofer, M. (2010). Quantification of Pseudomonas Combaret, C. (2018). Differential contribution of plant-beneficial functions from Pseudomonas kilonensis F113 to root system architecture alterations in Arabidopsis thaliana and Zea mays. Molecular Plant-Microbe Interactions, 31(2), 212-223.

Walker, V., Bruto, M., Bellvert, F., Bally, R., Muller, D., Prigent-Combaret, C., ... Comte, G. fluorescens strains $\mathrm{F} 113, \mathrm{CHA0}$ and $\mathrm{Pf} 153$ in the rhizosphere of maize by strain-specific real-time PCR unaffected by the variability of DNA extraction efficiency. Journal of Microbiological Methods, 81(2), 108-115. https://doi.org/10.1016/j.mimet.2010.02.003 (2013). Unexpected phytostimulatory behavior for Escherichia coli and Agrobacterium tumefaciens model strains. Molecular Plant-Microbe Interactions, 26(5), 495-502. https://doi.org/10.1094/MPMI-12-12-0298-R

Walker, V., Couillerot, O., von Felten, A., Bellvert, F., Jansa, J., Maurhofer, M., ... Comte, G. (2012). Variation of secondary metabolite levels in maize seedling roots induced by inoculation with Azospirillum, Pseudomonas and Glomus consortium under field

Walsh, U. F., Moënne-Loccoz, Y., Tichy, H. V., Gardner, A., Corkery, D. M., Lorkhe, S., \& conditions. Plant and Soil, 356(1-2), 151-163. https://doi.org/10.1007/s11104-011-0960O'Gara, F. (2003). Residual impact of the biocontrol inoculant Pseudomonas fluorescens F113 on the resident population of rhizobia nodulating a red clover rotation crop. Microbial Ecology, 45(2), 145-155. https://doi.org/10.1007/s00248-002-2026-8 causes the evolution of less-cooperative mutualists. Evolution, 69(3), 631-642. 
https://doi.org/10.1111/evo.12594

852

853

854

855

856

857

858

859

860

861

862

863

864

865

866

867

868

869

870

871

Wei, Z., \& Jousset, A. (2017). Plant breeding goes microbial. Trends in Plant Science, 22(7), 555-558. https://doi.org/10.1016/j.tplants.2017.05.009

West, S. A., Kiers, E. T., Simms, E. L., \& Denison, R. F. (2002). Sanctions and mutualism stability: Why do rhizobia fix nitrogen? Proceedings of the Royal Society B: Biological Sciences, 269(1492), 685-694. https://doi.org/10.1098/rspb.2001.1878

Winfield, M. O., Allen, A. M., Wilkinson, P. A., Burridge, A. J., Barker, G. L. A., Coghill, J., ... Edwards, K. J. (2018). High-density genotyping of the A.E. Watkins Collection of hexaploid landraces identifies a large molecular diversity compared to elite bread wheat. Plant Biotechnology Journal, 16(1), 165-175. https://doi.org/10.1111/pbi.12757

Wissuwa, M., Mazzola, M., \& Picard, C. (2009). Novel approaches in plant breeding for rhizosphere-related traits. Plant and Soil, 321(1-2), 409-430. https://doi.org/10.1007/s11104-008-9693-2

York, L. M., Galindo-Castañeda, T., Schussler, J. R., \& Lynch, J. P. (2015). Evolution of US maize (Zea mays L.) root architectural and anatomical phenes over the past 100 years corresponds to increased tolerance of nitrogen stress. Journal of Experimental Botany, 66(8), 2347-2358. https://doi.org/10.1093/jxb/erv074

Zhang, F. L., Niu, X. K., Zhang, Y. M., Xie, R. Z., Liu, X., Li, S. K., \& Gao, S. J. (2013). Studies on the root characteristics of maize varieties of different eras. Journal of Integrative Agriculture, 12(3), 426-435. https://doi.org/10.1016/S2095-3119(13)60243-9 


\section{Figure legends}

873

Fig. 1 Root colonization and phl expression of $P$. kilonensis F113-mCherry(Pphl-egfp) on 192 individual wheat genotypes corresponding to 115 modern genotypes (> 1960) and 77 ancient genotypes (including 42 old varieties [ $\leq 1960$ ] and 35 landraces). Red fluorescence (root colonization) is shown in (a), green fluorescence (phl expression) in (b), and the $p h l$ induction rate (green fluorescence:red fluorescence ratio) in (c). Fluorescence is expressed as arbitrary units (AU) and data are presented as means with standard errors $(n=3)$. The ranking of the 192 genotypes is indicated in Supporting information Table S1.

881

Fig. 2 Root colonization and phl expression of P. kilonensis F113-mCherry(Pphl-egfp) for modern $(n=115)$ and ancient wheat genotypes $(n=77)$. Red fluorescence (root colonization) is shown in (a), green fluorescence (phl expression) in (b), and the $p h l$ induction rate (red fluorescence:green fluorescence ratio) in (c). Fluorescence is expressed as arbitrary units (AU) and data are presented as means (computed from individual genotype data) with standard errors. Statistical differences between the two wheat categories are shown using letters $\mathrm{a}$ and $\mathrm{b}$ (Wilcoxon tests, $P<0.05)$.

Fig. 3 Frequency distribution of root colonization (red fluorescence, expressed as arbitrary units [AU]) and phl expression data (green fluorescence) of $P$. kilonensis F113-mCherry(Pphlegfp) for wheat genotypes. The frequency distribution of modern wheat genotypes $(n=115)$ is shown for root colonization data (a) and for phl expression data (b), and the frequencies were computed as the number of observations (i.e. of genotypes) in each of the 12 classes (red fluorescence) or 11 classes (red fluorescence) of fluorescence intensity divided by the total number of observations (i.e. 115). The deviation for the 77 ancient genotypes was computed by subtracting the frequencies for the 115 modern genotypes from the corresponding 898 frequencies for the 77 ancient genotypes in each of the fluorescence classes, both for root colonization data (c) and phl expression data (d). 
Fig. 4 Correlation analysis of root colonization data (red fluorescence, expressed as arbitrary

902

903

904

905

906

907

908

909

910

911

912

913 units $[\mathrm{AU}])(\mathbf{a})$ and $\mathrm{phl}$ expression data (green fluorescence) (b) of $P$. kilonensis F113$m$ Cherry(Pphl-egfp) obtained in the screening experiment ( $\mathrm{X}$ axis) and the verification experiment ( $Y$ axis) for 20 wheat genotypes. Spearman correlation coefficients were $r=0.80$ in (a) and $r=0.78$ in (b) (both with $P<0.001$ ).

Fig. 5 Root colonization by P. kilonensis F113-mCherry(Pphl-egfp) and phl expression at the surface of the apex of eight wheat genotypes (selected from the 20 genotypes studied) used for the validation experiment. Photographs were taken using a confocal microscope with an excitation laser light of $488 \mathrm{~nm}$ and an emission filter of 504-555 $\mathrm{nm}$ for EGFP green fluorescence, and an excitation laser light of $561 \mathrm{~nm}$ and an emission filter 570-636 nm for mCherry red fluorescence. The same gains were used for all samples. Root-colonizing cells not expressing $p h l$ are red, root-colonizing cells with strong phl expression (but with insufficient gain for red fluorescence) appear in green, and root-colonizing cells expressing phl are yellow. Large numbers of mainly red or yellow cells were obtained for genotypes Blé de Redon (Landrace) (A), Coronation ( $\leq 1960)(B)$, Concurrent $(\leq 1960)(C)$ and D130-63 (> 1960) (D), which had shown high red and green fluorescence values in the screening experiment, whereas fluorescent cells were sparse for genotypes Orlandi $(\leq 1960)(E)$, Orfield $(>1960)(F)$, Hendrix (> 1960) (G) and Jaszaji TF $(\leq 1960)(H)$, which had shown low red and green fluorescence values in the screening experiment.

Fig. 6 Relative impact of seed inoculation with P. kilonensis F113 on the growth of four F113stimulating wheat genotypes and four non F113-stimulating genotypes under optimum (a) or combined stress conditions (b), and relative impact of stress on performance of non-inoculated plants (c). For each of the nine plant parameters investigated, the relative impacts were computed as (inoculated - non-inoculated)/non-inoculated [in a,b], and (stress optimum)/optimum [in c]. The differences were not significant at $P<0.05$ level. 
Table 1 List of wheat genotypes used for the validation experiment in vitro and the greenhouse experiment in soil. All 20 genotypes were used for validation, whereas only the 8 genotypes in bold print were used for the greenhouse experiment. The total score indicated was the sum of the three genotype rankings, i.e. for $\mathrm{F} 113$ colonization, $\mathrm{phl}$ expression and $\mathrm{phl}$ induction rate. For each ranking, the worst rank (lower value measured) was 1 and the best rank (higher value measured) was 192.

\begin{tabular}{|c|c|c|c|}
\hline Global ranking & Genotype & Genotype category & Total score \\
\hline \multirow{7}{*}{$\begin{array}{l}\text { Among the } 1-20 \% \text { best } \\
\text { genotypes }\end{array}$} & D130-63 & $>1960$ & 570 \\
\hline & Coronation & $\leq 1960$ & 534 \\
\hline & Concurrent & $\leq 1960$ & 508 \\
\hline & Cenad 512 & $\leq 1960$ & 484 \\
\hline & DI276 & $>1960$ & 471 \\
\hline & Prince Leopold & $\leq 1960$ & 449 \\
\hline & ATUT-II & $>1960$ & 412 \\
\hline \multirow{3}{*}{$\begin{array}{l}\text { Among the } 20-40 \% \text { best } \\
\text { genotypes }\end{array}$} & Espoir & $\leq 1960$ & 394 \\
\hline & Blé de Redon glumes velues & Landrace & 385 \\
\hline & Amifort & $>1960$ & 350 \\
\hline \multirow{3}{*}{$\begin{array}{l}\text { Among the } 20-40 \% \text { worst } \\
\text { genotypes }\end{array}$} & Danubia & $>1960$ & 256 \\
\hline & Recital & $>1960$ & 202 \\
\hline & Croisement 268 & $\leq 1960$ & 182 \\
\hline \multirow{7}{*}{$\begin{array}{l}\text { Among the } 1-20 \% \text { worst } \\
\text { genotypes }\end{array}$} & Poilu du Tarn & $\leq 1960$ & 156 \\
\hline & Hendrix & $>1960$ & 154 \\
\hline & Jaszaji TF & $\leq 1960$ & 144 \\
\hline & Odesskaya 16 & $\leq 1960$ & 108 \\
\hline & Orlandi & $\leq 1960$ & 91 \\
\hline & Malgorzatka udycka & $\leq 1960$ & 85 \\
\hline & Orfield & $>1960$ & 64 \\
\hline
\end{tabular}


Table 2 Percentages of wheat genotypes showing the highest and lowest values of root colonization by $P$. kilonensis F113 or phl expression in root-colonizing F113 among the ancient ( $\mathrm{n}$ $=77)$ and modern genotypes $(n=115)$.

Ancient genotypes Modern genotypes

\section{Root colonization by F113}

25 best genotypes

$19.5 \% \mathrm{a}^{\dagger}$

$8.7 \% \mathrm{~b}$

50 best genotypes

$32.5 \%$ a

$21.7 \%$ a

50 worst genotypes

$20.8 \%$ a

$29.6 \%$ a

25 worst genotypes

$7.8 \%$ a

$16.5 \%$ a

\section{phl expression in F113}

25 best genotypes

50 best genotypes

50 worst genotypes

25 worst genotypes
$16.9 \%$ a

$35.1 \%$ a

$27.3 \%$ a

$7.8 \%$ a
$10.4 \%$ a

$20.0 \%$ b

$25.2 \%$ a

$16.5 \%$ a

${ }^{\dagger}$ For each row, significant differences between ancient and modern genotypes are indicated by letters $\mathrm{a}$ and $\mathrm{b}$ ( $\chi^{2}$ tests carried out on numbers of genotypes, $\left.P<0.05\right)$. 
Table 3 Relative impact of seed inoculation with $P$. kilonensis F113 on the growth of eight wheat genotypes under optimum or combined stress conditions. Concurrent, Coronation, Amifort and D130-63 are F113-stimulating genotypes, whereas Jaszaji TF, Odesskaya 16, Danubia and Hendrix are non F113-stimulating genotypes. For each of the nine plant parameters investigated, the relative impacts were computed as (inoculated - non-inoculated)/non-inoculated. For each genotype, significant differences between inoculated plants and controls are indicated in bold. Statistical level is indicated with * $(P \leq 0.05),{ }^{* *}(P \leq 0.01)$ or ${ }^{* * *}(P \leq 0.001)$, based on ANOVA and Fisher's LSD tests on raw plant values.

\begin{tabular}{|c|c|c|c|c|c|c|c|c|c|c|}
\hline & & Root volume & $\begin{array}{l}\begin{array}{l}\text { Fresh root } \\
\text { biomass }\end{array} \\
\end{array}$ & $\begin{array}{l}\text { Dry root } \\
\text { biomass }\end{array}$ & $\begin{array}{l}\text { Number of } \\
\text { Roots }\end{array}$ & $\begin{array}{l}\text { Root average } \\
\text { diameter }\end{array}$ & Root length & $\begin{array}{l}\text { Fresh shoot } \\
\text { biomass }\end{array}$ & $\begin{array}{l}\text { Dry shoot } \\
\text { biomass }\end{array}$ & Shoot height \\
\hline \multirow{8}{*}{ Optimum } & Concurrent & $-0.9 \%$ & $-23.0 \%$ & $-22.6 \%$ & $0.3 \%$ & $3.2 \%$ & $-6.6 \%$ & $-9.9 \%$ & $-10.1 \%$ & $0.2 \%$ \\
\hline & Coronation & $28.2 \%$ & $20.5 \%$ & $95.8 \%$ ** & $58.8 \%$ & $8.1 \%$ & $7.8 \%$ & $30.8 \%$ & $37.3 \%$ & $7.6 \%$ \\
\hline & Amifort & $14.8 \%$ & $-4.6 \%$ & $23.1 \%$ & $10.2 \%$ & $8.3 \%$ & $-0.7 \%$ & $-0.5 \%$ & $1.5 \%$ & $0.8 \%$ \\
\hline & D130-63 & $50.6 \%$ & $119.8 \%$ & $92.3 \%$ *** & $41.9 \%$ & $-1.4 \%$ & $46.1 \%$ & $18.4 \%$ & ND & $4.6 \%$ \\
\hline & Jaszaji TF & $-15.7 \%$ & $-20.0 \%$ & $-23.8 \%$ & $-10.0 \%$ & $3.3 \%$ & $-20.2 \%$ & $-12.8 \%$ & $-10.0 \%$ & $-7.6 \%$ \\
\hline & $\begin{array}{l}\text { Odesskaya } \\
16\end{array}$ & $39.1 \%$ & $61.9 \%$ & $103.4 \%$ *** & $10.1 \%$ & $-1.6 \%$ & $45.3 \%$ & $1.5 \%$ & ND & $-1.3 \%$ \\
\hline & Danubia & $5.6 \%$ & $-11.6 \%$ & $-2.7 \%$ & $26.0 \%$ & $7.1 \%$ & $-7.4 \%$ & $-1.4 \%$ & ND & $0.1 \%$ \\
\hline & Hendrix & $23.0 \%$ & $2.0 \%$ & $-8.5 \%$ & $47.5 \%$ & $4.1 \%$ & $11.7 \%$ & $4.5 \%$ & $7.9 \%$ & $-0.7 \%$ \\
\hline \multirow{8}{*}{ Stress } & Concurrent & $1.0 \%$ & $-5.7 \%$ & $-2.8 \%$ & $-13.7 \%$ & $11.7 \%$ ** & $-19.3 \%$ & $0.5 \%$ & $5.1 \%$ & $-4.0 \%$ \\
\hline & Coronation & $81.3 \%$ * & $65.8 \%$ & $79.3 \%$ ** & $102.3 \%$ *** & $1.9 \%$ & $71.7 \%$ & $5.9 \%$ & $12.4 \%$ & $4.2 \%$ \\
\hline & Amifort & $-35.5 \%$ & $-27.2 \%$ & $-35.3 \%$ * & $-50.4 \% * * *$ & $-4.9 \%$ & $-26.3 \%$ & $9.1 \%$ & $9.5 \%$ & $5.4 \%$ \\
\hline & D130-63 & $46.3 \%$ & $47.3 \%$ & $106.1 \%$ *** & $101.7 \%$ *** & $6.8 \%$ & $30.5 \%$ & $-4.8 \%$ & ND & $-2.7 \%$ \\
\hline & Jaszaji TF & $16.5 \%$ & $4.9 \%$ & $-26.0 \%$ & $19.8 \%$ & $4.7 \%$ & $8.6 \%$ & $8.3 \%$ & $17.9 \%$ & $0.5 \%$ \\
\hline & $\begin{array}{l}\text { Odesskaya } \\
16\end{array}$ & $9.9 \%$ & $6.4 \%$ & $6.9 \%$ & $8.4 \%$ & $1.1 \%$ & $11.8 \%$ & $-5.5 \%$ & ND & $-1.7 \%$ \\
\hline & Danubia & $6.4 \%$ & $-3.4 \%$ & $16.7 \%$ & $-5.9 \%$ & $7.8 \%$ & $-3.0 \%$ & $-4.1 \%$ & ND & $-2.7 \%$ \\
\hline & Hendrix & $17.5 \%$ & $4.6 \%$ & $-3.0 \%$ & $26.0 \%$ & $-2.6 \%$ & $28.6 \%$ & $-4.2 \%$ & $-1.8 \%$ & $-1.7 \%$ \\
\hline
\end{tabular}


Fig. 1
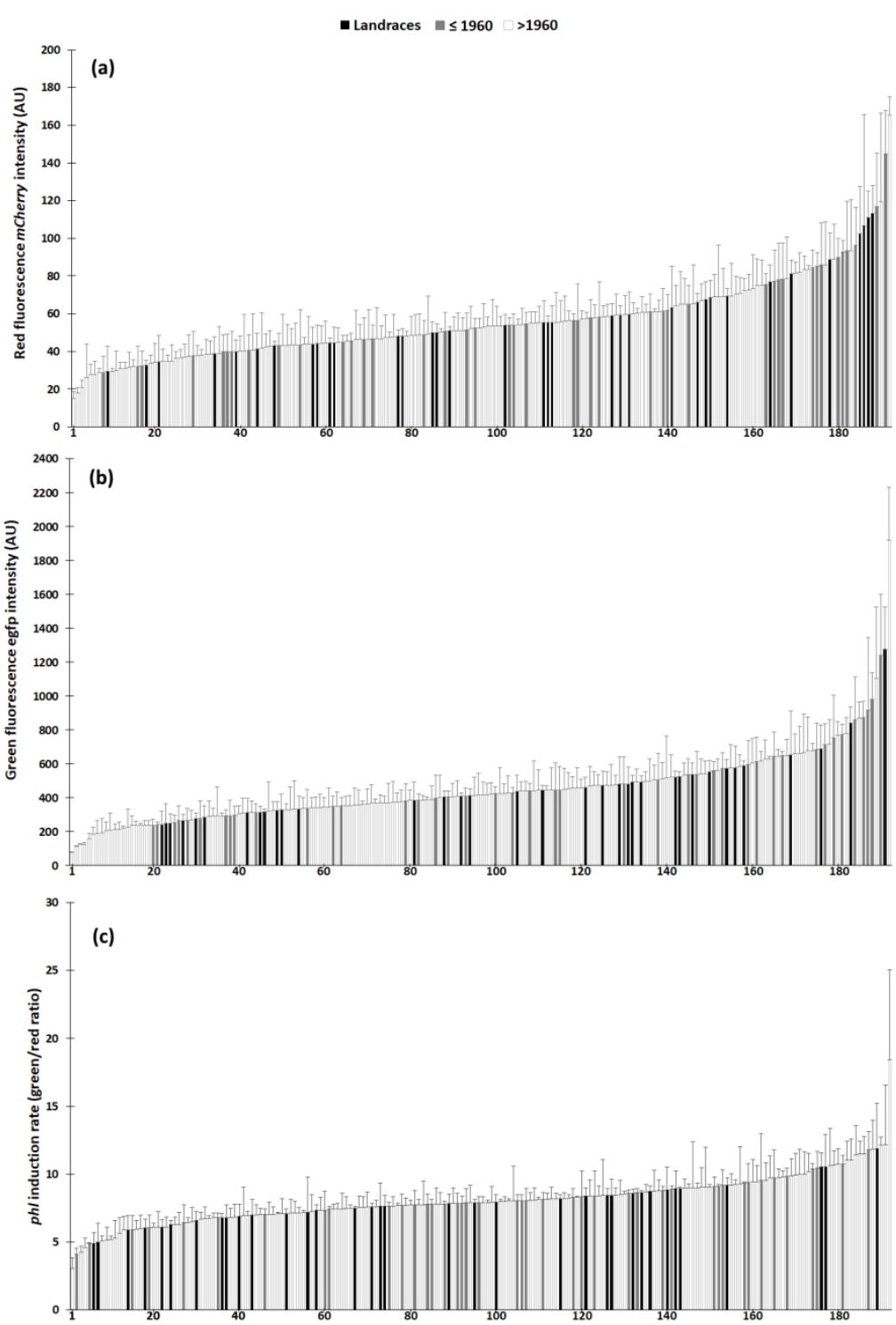

Figure 1

$353 \times 542 \mathrm{~mm}(96 \times 96$ DPI $)$ 
Fig. 2
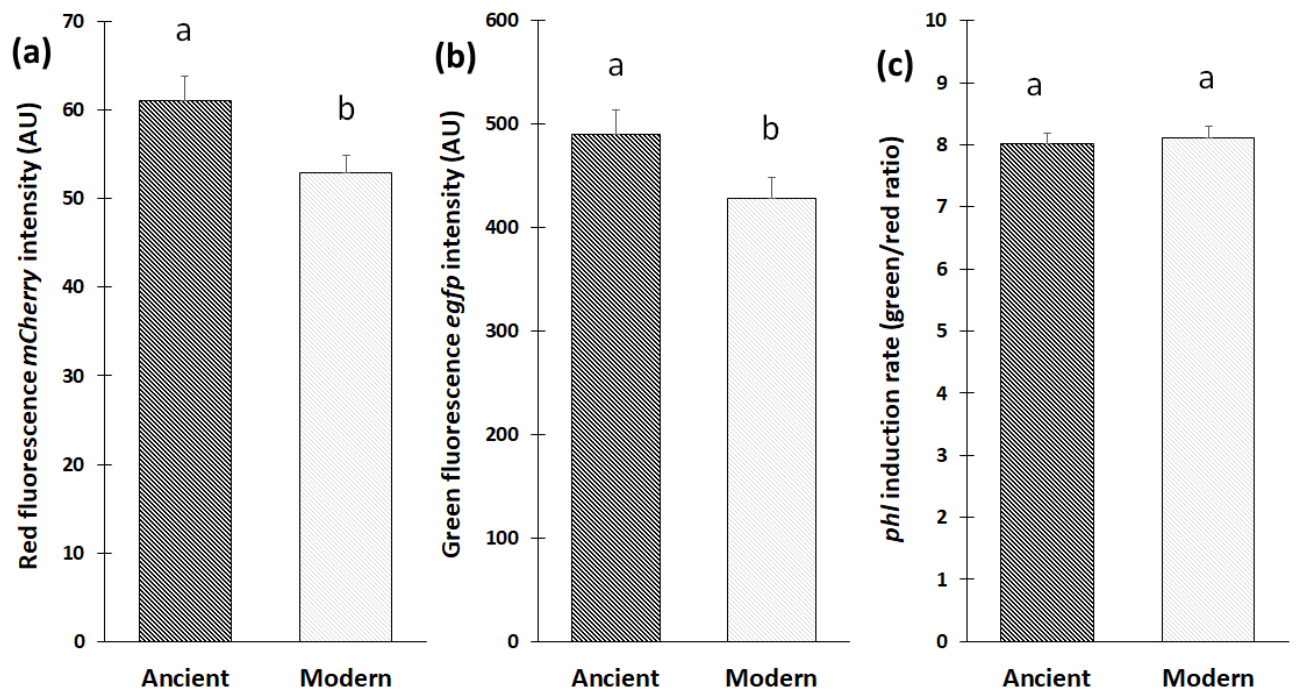

Figure 2

$296 \times 177 \mathrm{~mm}(96 \times 96 \mathrm{DPI})$ 
Fig. 3

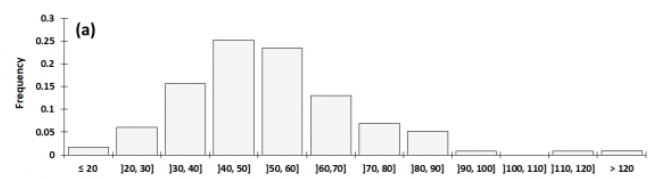

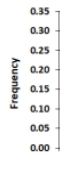
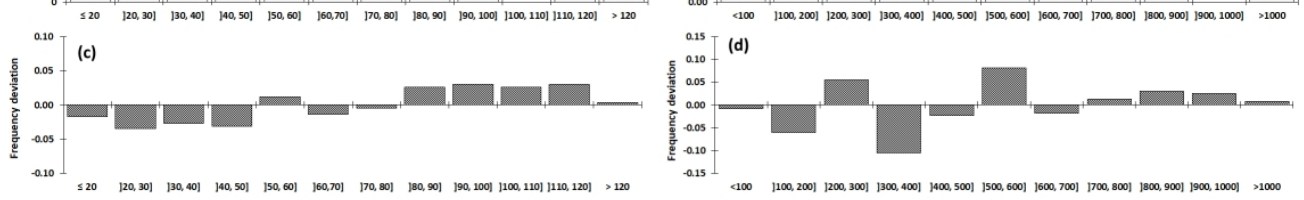

Figure 3

$605 \times 177 \mathrm{~mm}(96 \times 96$ DPI $)$ 

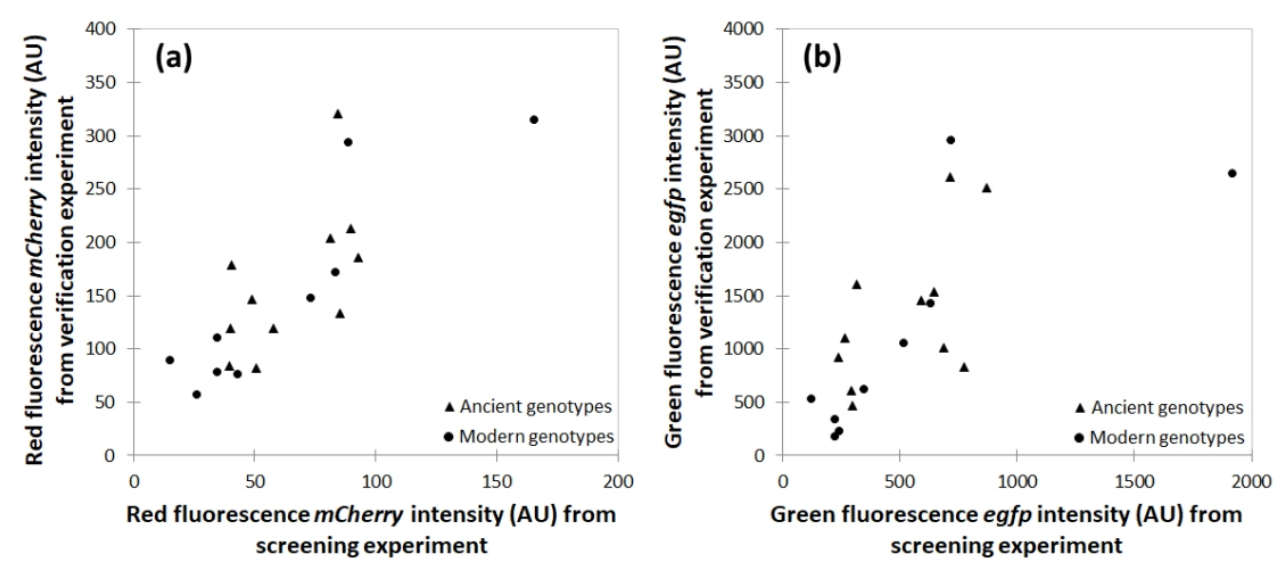

Fig. 4

Figure 4

$320 \times 158 \mathrm{~mm}(96 \times 96$ DPI $)$ 
Fig. 5

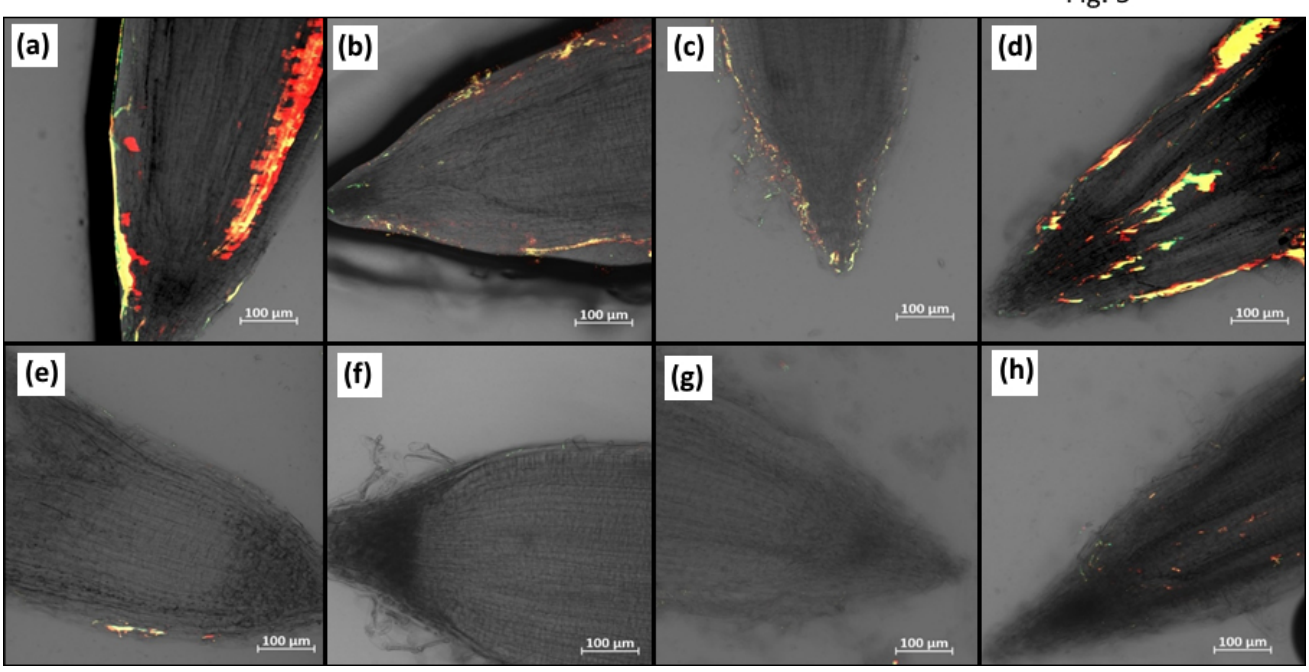

Figure 5

$239 \times 126 \mathrm{~mm}(96 \times 96$ DPI $)$ 
QF113-stimulating $\mathbf{T}$ Non F113-stimulating
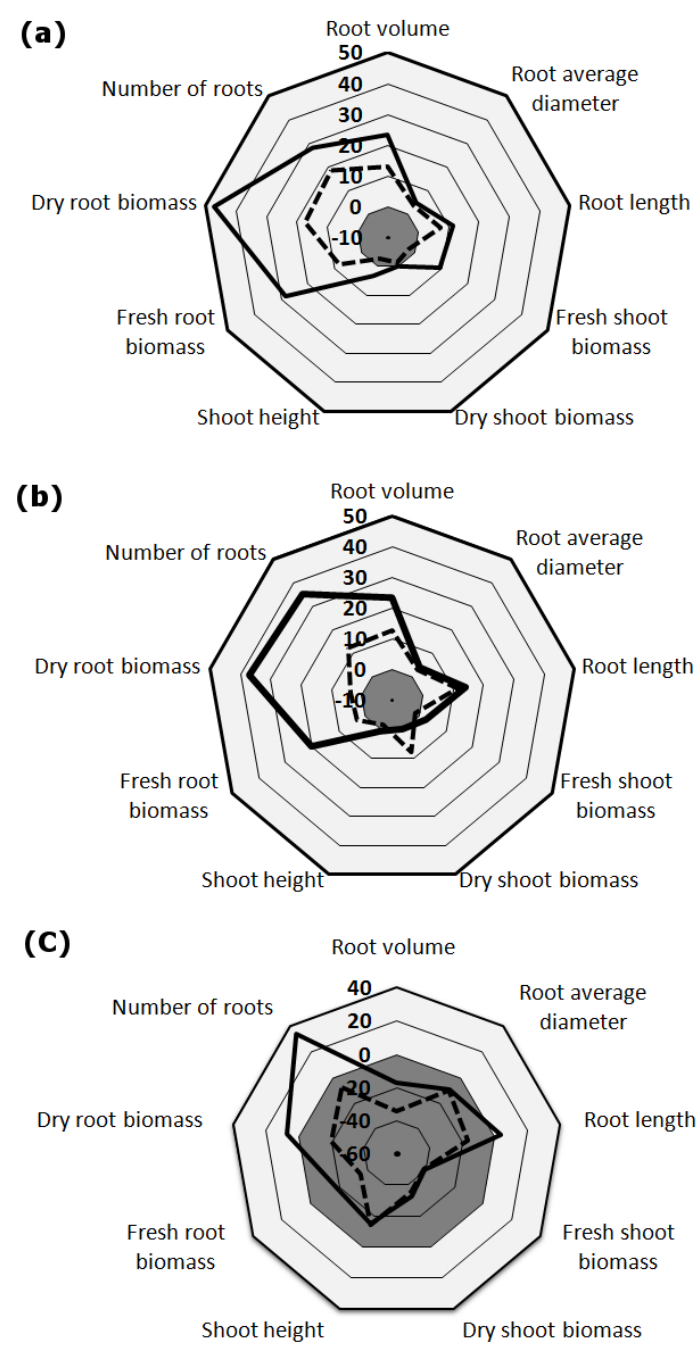

Fig. 6

Figure 6

$182 \times 363 \mathrm{~mm}(96 \times 96 \mathrm{DPI})$ 